Published in final edited form as:

Exp Cell Res. 2012 May 15; 318(9): 973-978. doi:10.1016/j.yexcr.2012.02.031.

\title{
The Glomerular Basement Membrane
}

\author{
Jeffrey $\mathrm{H}$. Miner \\ Renal Division and Dept. of Cell Biology and Physiology, Washington University School of \\ Medicine, 660 S. Euclid Ave., Campus Box 8126, St. Louis, MO 63110, USA
}

\begin{abstract}
The kidney's glomerular filtration barrier consists of two cells—-podocytes and endothelial cellsand the glomerular basement membrane (GBM), a specialized extracellular matrix that lies between them. Like all basement membranes, the GBM consists mainly of laminin, type IV collagen, nidogen, and heparan sulfate proteoglycan. However, the GBM is unusually thick and contains particular members of these general protein families, including laminin-521, collagen a $3 a 4 a 5(I V)$, and agrin. Knockout studies in mice and genetic findings in humans shows that the laminin and type IV collagen components are particularly important for GBM structure and function, as laminin or collagen IV gene mutations cause filtration defects and renal disease of varying severities, depending on the nature of the mutations. These studies suggest that the GBM plays a crucial role in establishing and maintaining the glomerular filtration barrier.
\end{abstract}

\section{Keywords \\ laminin; collagen IV; Alport syndrome; Pierson syndrome}

\section{Introduction}

The glomerular basement membrane (GBM) is the extracellular matrix component of the selectively permeable glomerular filtration barrier (GFB) that separates the vasculature from the urinary space. The GBM lies between, and is initially synthesized by, the glomerular endothelial cells that line the glomerular capillaries and the podocytes (also called visceral epithelial cells) that sit on the opposite side of the GBM within the urinary space (Fig. 1). This three-layered structure-endothelium, GBM, and podocyte-facilitates the flow of plasma water and small solutes while restricting the flow of large plasma proteins such as albumin. The presence of high levels of albumin in the urine is considered to be indicative of a defect in at least one of the layers of the GFB.

The glomerular endothelial cells and podocytes are highly specialized cells. The endothelium bears fenestrations (transcellular "windows") that presumably allow the plasma flowing through the capillaries to reach the GBM, although there is evidence that the fenestrations are plugged by a glycocalyx-like material that imparts barrier properties [1]. The podocytes send out a multitude of extensions called foot processes that interdigitate with those of adjacent podocytes and cover the outer aspect of the glomerular capillary (Fig.

(C) 2012 Elsevier Inc. All rights reserved.

Fax: +1-314-362-8237, minerj@wustl.edu.

Publisher's Disclaimer: This is a PDF file of an unedited manuscript that has been accepted for publication. As a service to our customers we are providing this early version of the manuscript. The manuscript will undergo copyediting, typesetting, and review of the resulting proof before it is published in its final citable form. Please note that during the production process errors may be discovered which could affect the content, and all legal disclaimers that apply to the journal pertain. 
1). The foot processes are connected by a unique cell-cell junction called the slit diaphragm that maintains defined spacing between the processes and at the same time permits the efficient flow of water and small solutes across the filtration barrier [2].

Because a major physiological property of the GFB is its ability to restrict the flow of plasma proteins such as albumin into the urinary space, there has been intense interest in defining the specific structure that imparts the GFB with this ability. Since the GFB was first visualized by electron microscopy in the 1950's, the GBM and the slit diaphragm have been the subjects of intense debate among nephrologists, anatomists, and pathologists regarding which one constitutes the major barrier to albumin [3]. Although the debate has not been settled, what is clear is that defects in either the GBM or in the slit diaphragm can cause leakage of albumin into the urine (albuminuria) and the nephrotic syndrome, characterized by high albuminuria, low plasma albumin, high plasmid lipid, and edema. More recently the glomerular endothelium and its surface glycocalyx have entered into this debate, as it is clear that injury to the endothelium, as occurs in preeclampsia or as a side effect of certain drugs that affect the vascular endothelial growth factor signaling axis, can also cause proteinuria [4].

The focus of this review is the GBM. Like all basement membranes, the GBM is a sheet-like extracellular matrix composed of four major macromolecules: laminin, type IV collagen, nidogen, and heparan sulfate proteoglycan, the major one in the GBM being agrin (Fig. 2) [5]. Studies over the past two and a half decades have shown that 1) the GBM contains specific basement membrane protein isoforms; 2) some of these isoforms are crucial for glomerular development, morphology, and function; and 3) mutations in four of the nine known genes that encode the GBM's components cause human kidney disease. The purpose of this review is to summarize the major findings regarding these aspects of the GBM, focusing on the specific basement membrane protein isoforms present within it.

\section{Laminin}

Laminin is a ubiquitous basement membrane component that actually describes a family of several different isoforms. All laminins are secreted as $\alpha \beta \gamma$ heterotrimers, the structures of which are stabilized by limited interchain disulfide bonding. There are five $\alpha$, four $\beta$, and three $\gamma$ chains that assemble with each other nonrandomly to form at least 15 different heterotrimers. Laminin heterotrimers are named based upon the specific $\alpha \beta \gamma$ chain composition; for example, laminin $\alpha 2 \beta 2 \gamma 1$ is referred to as laminin-221 or LM-221 [6]. An excellent discussion of laminin chain diversity and evolution was recently published [7].

Laminin chains are evolutionarily related to each other and therefore share a number of structural features. The typical laminin heterotrimer is schematized as a cross-shaped structure in which the three chains wrap around each other via their laminin coiled-coil (LCC) domains to form the lower long arm of the cross (Fig. 2). Extending past this arm is a large (approximately 900 amino acid) laminin globular (LG) domain that is found at the $\mathrm{COOH}$ termini of all five a chains. The LG domains contain five tandem subdomains that bear binding sites for cell surface receptors such as integrins and dystroglycan. The three other arms of the cross, termed short arms, are formed by alternating globular and rod-like domains (Fig. 2). Of note, the globular laminin N-terminal (LN) domain is responsible for mediating the trimer-trimer interactions in the extracellular matrix that lead to formation of the laminin polymer and initiation of basement membrane assembly [8]. The rod-like domains are composed of laminin-type epidermal growth factor-like (LE) repeats whose secondary structure depends upon extensive disulfide bonding.

As far as the mature GBM is concerned, the major laminin is LM-521. However, during the processes of GBM formation and maturation that occur during glomerulogenesis, there are 
developmental transitions in laminin trimer deposition. These transitions can be briefly summarized as LM-111 to LM-511 to LM-521 [9-11].

The importance of these laminin transitions is revealed by the effects of mutations that prevent them from occurring. For example, a null mutation of laminin a5 (Lama5) in mice prevents the LM-111 to LM-511 transition and results in breakdown of the GBM and subsequent failure of glomerular vascularization [12]. GBM breakdown presumably occurs due to the lack of a sufficient concentration of polymerized laminin trimers, as the laminin network is required to maintain basement membrane integrity [13]. In support of this, a hypomorphic mutation in Lama5 caused by insertion of a neo cassette that impairs splicing of the laminin a 5 mRNA results in reduced levels of laminin a 5 in the GBM as well as in tubular basement membranes, but there appear to be sufficient levels of laminin a5containing trimers to maintain GBM integrity. However, the reduction from the normal laminin level causes glomerular proteinuria and hematuria and, unexpectedly, polycystic kidneys and renal failure within a month [14]. Although this provided long sought support for the hypothesis that impaired tubular epithelial cell-matrix interactions might be involved in cystogenesis, subsequent studies showed the cystic phenotype to be due solely to the defective GBM [14].

Mutation of laminin $\beta 2$ (Lamb2) either in mice or humans results in a congenital nephrotic syndrome with variable ocular and neurological manifestations, which in humans is called Pierson syndrome $[15,16]$. Our data suggests that the reduced LM-521 results in ectopic deposition of other laminin trimers that cannot make a properly permselective GBM, leading to leakage of albumin across the glomerular filtration barrier and nephrotic syndrome [17]. We recently tested the hypothesis that it is not the lack of laminin $\beta 2$ per se but rather the lack of a sufficient concentration of laminin a5-containing trimers that causes nephrotic syndrome. Indeed, by overexpressing laminin $\beta 1$ in podocytes on the Lamb2-/- background we could successfully prevent the nephrotic syndrome, and this correlated with high level deposition of LM-511 in the GBM [18].

\section{Collagen IV}

Like most collagens, type IV collagen is a trimeric extracellular matrix protein consisting of a chains that are rich in Gly-X-Y amino acid triplet repeats. Three a chains wind around one another to form the collagen triple helix (Fig. 2); the Gly at every third position is necessary because it is the only amino acid with a side chain small enough to fit at the center of the helix. But unlike most other collagen types, type IV collagens have interruptions of the Gly-X-Y repeats, presumably to make a more flexible trimer and a more flexible network that imparts basement membranes with the flexibility that is likely important for their function.

The collagen IV family consists of six genetically distinct a chains that trimerize with each other in specific stoichiometries to make three different types of network-forming building blocks called protomers. These include the $(a 1)_{2} a 2, a 3 a 4 a 5$, and $(a 5)_{2} a 6$ protomers. Protomers are secreted into the extracellular matrix, where they self-polymerize via their $\mathrm{NH} 2$ - and $\mathrm{COOH}$-terminal domains to make a network within the plane of the basement membrane that becomes crosslinked due to the activity of several secreted enzymes. Although basement membranes can form in the absence of type IV collagen, the collagen IV network is crucial for basement membrane stability [19].

Like GBM laminin developmental transitions, there are also type IV collagen transitions during glomerulogenesis. Initially the nascent GBM contains the a 1/a 2 network, but as the glomerular capillaries begin to form and function the podocytes (but not the endothelial cells) begin to secrete a $3 a 4 a 5$ trimers. These then polymerize to form what will become the 
mature GBM collagen IV network, and the a 1/a 2 network becomes a minor component $[11,20]$.

Mutations that affect the genes encoding any one of the collagen IV a 3, a 4, or a 5 chains can cause defects in the GBM. The defects can be mild, as in thin basement membrane disease, or severe, as in Alport syndrome. Thin basement membrane disease, also called benign familial hematuria, shows autosomal dominant inheritance and has been found in 40 to $50 \%$ of patients to result from heterozygous null mutations in $C O L 4 A 3$ or $C O L 4 A 4$, which encode the a 3 and a 4 chains of type IV collagen, respectively. As the alternate disease names imply, affected individuals exhibit thinning of the GBM and blood in the urine but do not usually progress to overt renal disease requiring treatment. However, these same $C O L 4 A 3$ and $C O L 4 A 4$ mutations in the homozygous state cause autosomal recessive Alport syndrome, a basement membrane disease leading to eventual kidney failure that is associated with deafness and ocular abnormalities. The most common version of Alport syndrome is the X-linked form, which is caused by mutations in COL4A5. Both the autosomal and X-linked forms of Alport syndrome share the same glomerular histopathology; there is both thinning of the GBM and variable segmental thickening of the GBM that by electron microscopy imparts a basket weave appearance rather than the typical ribbon-like morphology (Fig. 3).

Why do these COL4 mutations cause these different diseases? Logically, because the great majority of GBM protomers are obligate a $3 a 4 a 5$ (IV) heterotrimers, reduced levels or any one of these three chains (as in thin basement membrane disease) could reduce the quantity of protomer secreted, and this could theoretically impact the density of the collagen IV network and therefore the architecture of the GBM. On the other hand, complete absence of a $3 a 4 a 5$ (IV) network due to the total lack of one of these chains, as in Alport syndrome, is expected to cause more severe GBM abnormalities. In the absence of this network, there seems to be increased accumulation of the $(\mathrm{a} 1)_{2} \mathrm{a} 2$ network as an attempt to compensate, but the severe ultrastructural abnormalities and eventual progressive scarring of glomeruli that impairs kidney function indicates that compensation is not complete. It has been proposed that the a $3 a 4 a 5$ (IV) network is more resistant to proteases and can be more highly crosslinked compared to the $(\mathrm{a} 1)_{2}$ a 2 network, resulting in superior stability that can maintain GBM architecture.

As logical as these zygosity-phenotype correlations seem to be for Alport syndrome and thin basement membrane disease, a less clear issue is why mutations in $C O L 4 A 1$ can cause kidney disease and systemic extrarenal manifestations, including brain structural defects. Hereditary angiopathy with nephropathy, aneurysms, and muscle cramps (HANAC) syndrome is a recently described disease entity associated with hematuria and bilateral large cysts [21]. The syndrome is caused by heterozygous glycine substitutions in a particular region of COL4A1, the CB3[IV] domain [21,22]. This domain is particularly important for integrin binding to collagen IV [23], so the mutations may impact the avidity of cell/matrix interactions at the affected sites. Heterozygous mutations in other regions of COL4A1 have been shown to cause stroke, porencephaly, and small vessel disease in both humans and mice [24], and kidney basement membrane defects have been observed in mutant mice $[25,26]$. Additional studies are necessary to determine the mechanism of disease pathogenesis in these patients and in the corresponding mutant mice.

\section{Nidogen}

There are two nidogen proteins, nidogen-1 and nidogen-2 (previously also known as entactin-1 and entactin-2). Both are dumbbell-shaped (Fig. 2), virtually ubiquitous basement membrane proteins. Because of its earlier discovery, much more is known about the 
biochemistry and function of nidogen-1. Nidogen-1 binds both laminin and type IV collagen, and because of this it was originally proposed to link the separate laminin and collagen IV networks [27] and to therefore be crucial for basement membrane formation. However, the results from generating nidogen- 1 and nidogen- 2 mutant mice did not fully agree with this assessment. The individual mutants are actually viable and fertile with apparently normal basement membranes [28,29], which was somewhat surprising until one considers that the two proteins are at least partially redundant in their abilities to bind both laminin and type IV collagen [30]. Consistent with this, deletion of both nidogen genes results in perinatal lethality [31]. However, another surprise was that basement membranes could form in the absence of both nidogens, and most organogenetic programs proceeded normally. The major exceptions were defects in the late stages of lung development and in maintenance/integrity of cardiac muscle that were associated with basement membrane alterations. Although most kidneys were fully formed, there was occasional renal dysgenesis or agenesis, or hydronephrosis or dilation of the ureteric bud derivatives, but the GBM had a normal appearance [31].

\section{Agrin}

Agrin is the major heparan sulfate proteoglycan of the GBM [32]. There are multiple splice forms of agrin, one of which is present in the basement membrane of the synaptic cleft at the neuromuscular junction, where it has been shown to be critical for localization and differentiation of neuromuscular synapses [33]. In addition, although the secreted form of agrin is present in the GBM, some neuronal cells express a transmembrane form of agrin through the use of an alternative promoter [34]. This transmembrane form seems to be important for inducing the formation of neuronal processes [35] but is not involved in organizing neuromuscular junctions [34].

As a heparan sulfate proteoglycan, agrin has a high net negative charge due to the presence of sulfated glycosaminoglycan (GAG) side chains (Fig. 2). Because all basement membranes, and the GBM in particular, exhibit a net negative charge, heparan sulfate proteoglycans such as perlecan and agrin are presumed to be important contributors towards this negative charge [36]. It has long been accepted dogma in the field of renal physiology that the net negative charge of the GBM is a crucial component of the glomerular capillary wall's filtration barrier to plasma albumin, which is also negatively charged and should therefore be repelled by the GBM. Indeed, classic studies showed that for tracer molecules presumed to be of similar size, positively charged ones cross the filtration barrier more readily than neutral ones, which cross more readily than negatively charged ones [37]. However, the concept of charge selectivity has recently been called into question by different types of studies. For example, when we removed agrin from the GBM by podocyte-selective knockout of $A g r n$, we could detect a dramatic reduction in GBM anionic charge (Fig. 4) yet no effect on the glomerular filtration barrier either to albumin or to a negatively charged tracer [38]. And although perlecan is at most a minor component of the mature GBM, we went on to show that removal of both heparan sulfate-linked perlecan and agrin from the GBM was also compatible with a normal filtration barrier [39]. Furthermore, reduction of GBM anionic charge in vivo by infusion of heparanase, which removes heparan sulfate side chains from proteoglycans, does not lead to proteinuria [40]. In a different type of approach, Rippe and colleagues used charged and neutral fluorescein isothiocyanate (FITC)-labeled Ficolls of varying sizes as tracers in anesthetized rats and found that there was a noticeable charge effect (inhibition of diffusion) for molecules of 20-35 larger molecules of 35 to $80 \AA$ [41]. They concluded that GBM charge plays a minor role, primarily for "small pores", in imparting the glomerular filter with charge selectivity and suggested that the endothelial glycocalyx may be more important [42], but that overall the charge selective properties of the glomerular filter are weaker than previously envisioned 
[41]. Recently, an exciting new model to explain the charge-selective nature of the glomerular filtration barrier was presented; in this model, the charge barrier is formed by glomerular filtration itself, and albumin is essentially "electrophoresed" away from the urinary space and towards the capillary lumen [43].

\section{Conclusions}

Studies of the glomerular basement membrane by anatomists, biochemists, geneticists, and cell and developmental biologists over the past few decades have led to a basic understanding of its composition, structure, genesis, and function. Although there is still much to be learned about GBM and what it really does, the ability to manipulate its composition or dynamics in the future could have important implications for the treatment of glomerular disease.

\section{Acknowledgments}

My relevant research is supported by NIH grants R01DK078314, R01GM060432, and P30DK079333.

\section{REFERENCES}

[1]. Haraldsson B, Jeansson M. Glomerular filtration barrier. Curr. Opin. Nephrol. Hypertens. 2009; 18:331-335. [PubMed: 19458528]

[2]. Simons M, Huber TB. It's not all about nephrin. Kidney Int. 2008; 73:671-673. [PubMed: 18309348]

[3]. Farquhar MG. Editorial: The primary glomerular filtration barrier--basement membrane or epithelial slits? Kidney Int. 1975; 8:197-211. [PubMed: 1104965]

[4]. Maynard SE, Karumanchi SA. Angiogenic factors and preeclampsia. Semin. Nephrol. 2011; 31:33-46. [PubMed: 21266263]

[5]. Timpl R. Structure and biological activity of basement membrane proteins. Eur. J. Biochem. 1989; 180:487-502. [PubMed: 2653817]

[6]. Aumailley M, Bruckner-Tuderman L, Carter WG, Deutzmann R, Edgar D, Ekblom P, Engel J, Engvall E, Hohenester E, Jones JC, Kleinman HK, Marinkovich MP, Martin GR, Mayer U, Meneguzzi G, Miner JH, Miyazaki K, Patarroyo M, Paulsson M, Quaranta V, Sanes JR, Sasaki T, Sekiguchi K, Sorokin LM, Talts JF, Tryggvason K, Uitto J, Virtanen I, von der Mark K, Wewer UM, Yamada Y, Yurchenco PD. A simplified laminin nomenclature. Matrix Biol. 2005; 24:326-332. [PubMed: 15979864]

[7]. Sztal T, Berger S, Currie PD, Hall TE. Characterization of the laminin gene family and evolution in zebrafish. Dev. Dyn. 2011; 240:422-431. [PubMed: 21246659]

[8]. McKee KK, Harrison D, Capizzi S, Yurchenco PD. Role of laminin terminal globular domains in basement membrane assembly. J. Biol. Chem. 2007; 282:21437-21447. [PubMed: 17517882]

[9]. Miner JH. Developmental biology of glomerular basement membrane components. Curr. Opin. Nephrol. Hypertens. 1998; 7:13-19. [PubMed: 9442357]

[10]. Miner JH, Patton BL, Lentz SI, Gilbert DJ, Snider WD, Jenkins NA, Copeland NG, Sanes JR. The laminin alpha chains: expression, developmental transitions, and chromosomal locations of alpha1-5, identification of heterotrimeric laminins 8-11, and cloning of a novel alpha3 isoform. J. Cell Biol. 1997; 137:685-701. [PubMed: 9151674]

[11]. Miner JH, Sanes JR. Collagen IV a3, a 4, and a 5 chains in rodent basal laminae: Sequence, distribution, association with laminins, and developmental switches. J. Cell Biol. 1994; 127:879_ 891. [PubMed: 7962065]

[12]. Miner JH, Li C. Defective glomerulogenesis in the absence of laminin a 5 demonstrates a developmental role for the kidney glomerular basement membrane. Dev. Biol. 2000; 217:278289. [PubMed: 10625553] 
[13]. Smyth N, Vatansever HS, Murray P, Meyer M, Frie C, Paulsson M, Edgar D. Absence of basement membranes after targeting the LAMC1 gene results in embryonic lethality due to failure of endoderm differentiation. J. Cell Biol. 1999; 144:151-160. [PubMed: 9885251]

[14]. Shannon MB, Patton BL, Harvey SJ, Miner JH. A hypomorphic mutation in the mouse Laminin alpha5 gene (Lama5) causes polycystic kidney disease. J. Am. Soc. Nephrol. 2006; 17:19131922. [PubMed: 16790509]

[15]. Matejas V, Hinkes B, Alkandari F, Al-Gazali L, Annexstad E, Aytac MB, Barrow M, Blahova K, Bockenhauer D, Cheong HI, Maruniak-Chudek I, Cochat P, Dotsch J, Gajjar P, Hennekam RC, Janssen F, Kagan M, Kariminejad A, Kemper MJ, Koenig J, Kogan J, Kroes HY, KuwertzBroking E, Lewanda AF, Medeira A, Muscheites J, Niaudet P, Pierson M, Saggar A, Seaver L, Suri M, Tsygin A, Wuhl E, Zurowska A, Uebe S, Hildebrandt F, Antignac C, Zenker M. Mutations in the human laminin beta2 (LAMB2) gene and the associated phenotypic spectrum. Hum. Mutat. 2010; 31:992-1002. [PubMed: 20556798]

[16]. Noakes PG, Miner JH, Gautam M, Cunningham JM, Sanes JR, Merlie JP. The renal glomerulus of mice lacking s-laminin/laminin beta2: nephrosis despite molecular compensation by laminin beta1. Nat. Genet. 1995; 10:400-406. [PubMed: 7670489]

[17]. Jarad G, Cunningham J, Shaw AS, Miner JH. Proteinuria precedes podocyte abnormalities in Lamb2-/- mice, implicating the glomerular basement membrane as an albumin barrier. J. Clin. Invest. 2006; 116:2272-2279. [PubMed: 16886065]

[18]. Suh JH, Jarad G, Vandevoorde RG, Miner JH. Forced expression of laminin \{beta\}1 in podocytes prevents nephrotic syndrome in mice lacking laminin \{beta\}2, a model for Pierson syndrome. Proc. Natl. Acad. Sci. USA. 2011; 108:15348-15353. [PubMed: 21876163]

[19]. Poschl E, Schlotzer-Schrehardt U, Brachvogel B, Saito K, Ninomiya Y, Mayer U. Collagen IV is essential for basement membrane stability but dispensable for initiation of its assembly during early development. Development. 2004; 131:1619-1628. [PubMed: 14998921]

[20]. Abrahamson DR, Hudson BG, Stroganova L, Borza DB, St John PL. Cellular origins of type IV collagen networks in developing glomeruli. J. Am. Soc. Nephrol. 2009; 20:1471-1479. [PubMed: 19423686]

[21]. Plaisier E, Gribouval O, Alamowitch S, Mougenot B, Prost C, Verpont MC, Marro B, Desmettre T, Cohen SY, Roullet E, Dracon M, Fardeau M, Van Agtmael T, Kerjaschki D, Antignac C, Ronco P. COL4A1 mutations and hereditary angiopathy, nephropathy, aneurysms, and muscle cramps. N. Engl. J. Med. 2007; 357:2687-2695. [PubMed: 18160688]

[22]. Plaisier E, Chen Z, Gekeler F, Benhassine S, Dahan K, Marro B, Alamowitch S, Paques M, Ronco P. Novel COL4A1 mutations associated with HANAC syndrome: a role for the triple helical CB3[IV] domain. Am. J. Med. Genet. A. 2010; 152A:2550-2555. [PubMed: 20818663]

[23]. Eble JA, Golbik R, Mann K, Kuhn K. The alpha 1 beta 1 integrin recognition site of the basement membrane collagen molecule [alpha 1(IV)]2 alpha 2(IV). EMBO J. 1993; 12:4795-4802. [PubMed: 8223488]

[24]. Gould DB, Phalan FC, Breedveld GJ, van Mil SE, Smith RS, Schimenti JC, Aguglia U, van der Knaap MS, Heutink P, John SW. Mutations in Col4a1 cause perinatal cerebral hemorrhage and porencephaly. Science. 2005; 308:1167-1171. [PubMed: 15905400]

[25]. Gould DB, Phalan FC, van Mil SE, Sundberg JP, Vahedi K, Massin P, Bousser MG, Heutink P, Miner JH, Tournier-Lasserve E, John SW. Role of COL4A1 in small-vessel disease and hemorrhagic stroke. N. Engl. J. Med. 2006; 354:1489-1496. [PubMed: 16598045]

[26]. Van Agtmael T, Schlotzer-Schrehardt U, McKie L, Brownstein DG, Lee AW, Cross SH, Sado Y, Mullins JJ, Poschl E, Jackson IJ. Dominant mutations of Col4a1 result in basement membrane defects which lead to anterior segment dysgenesis and glomerulopathy. Hum. Mol. Genet. 2005; 14:3161-3168. [PubMed: 16159887]

[27]. Fox JW, Mayer U, Nischt R, Aumailley M, Reinhardt D, Wiedemann H, Mann K, Timpl R, Krieg T, Engel J. Recombinant nidogen consists of three globular domains and mediates binding of laminin to collagen type IV. EMBO J. 1991; 10:3137-3146. [PubMed: 1717261]

[28]. Murshed M, Smyth N, Miosge N, Karolat J, Krieg T, Paulsson M, Nischt R. The absence of nidogen 1 does not affect murine basement membrane formation. Mol. Cell. Biol. 2000; 20:7007-7012. [PubMed: 10958695] 
[29]. Schymeinsky J, Nedbal S, Miosge N, Poschl E, Rao C, Beier DR, Skarnes WC, Timpl R, Bader BL. Gene structure and functional analysis of the mouse nidogen-2 gene: nidogen-2 is not essential for basement membrane formation in mice. Mol. Cell. Biol. 2002; 22:6820-6830. [PubMed: 12215539]

[30]. Miosge N, Sasaki T, Timpl R. Evidence of nidogen-2 compensation for nidogen-1 deficiency in transgenic mice. Matrix Biol. 2002; 21:611-621. [PubMed: 12475645]

[31]. Bader BL, Smyth N, Nedbal S, Miosge N, Baranowsky A, Mokkapati S, Murshed M, Nischt R. Compound genetic ablation of nidogen 1 and 2 causes basement membrane defects and perinatal lethality in mice. Mol. Cell. Biol. 2005; 25:6846-6856. [PubMed: 16024816]

[32]. Groffen AJ, Ruegg MA, Dijkman H, van de Velden TJ, Buskens CA, van den Born J, Assmann KJ, Monnens LA, Veerkamp JH, van den Heuvel LP. Agrin is a major heparan sulfate proteoglycan in the human glomerular basement membrane. J. Histochem. Cytochem. 1998; 46:19-27. [PubMed: 9405491]

[33]. Burgess RW, Nguyen QT, Son YJ, Lichtman JW, Sanes JR. Alternatively spliced isoforms of nerve- and muscle-derived agrin: their roles at the neuromuscular junction. Neuron. 1999; 23:3344. [PubMed: 10402191]

[34]. Burgess RW, Skarnes WC, Sanes JR. Agrin isoforms with distinct amino termini: differential expression, localization, and function. J. Cell Biol. 2000; 151:41-52. [PubMed: 11018052]

[35]. Ramseger R, White R, Kroger S. Transmembrane form agrin-induced process formation requires lipid rafts and the activation of Fyn and MAPK. J. Biol. Chem. 2009; 284:7697-7705. [PubMed: 19139104]

[36]. Kanwar YS, Danesh FR, Chugh SS. Contribution of Proteoglycans Towards the Integrated Functions of Renal Glomerular Capillaries. A Historical Perspective. Am. J. Pathol. 2007; 171:913. [PubMed: 17591948]

[37]. Bohrer MP, Baylis C, Humes HD, Glassock RJ, Robertson CR, Brenner BM. Permselectivity of the glomerular capillary wall. Facilitated filtration of circulating polycations. J. Clin. Invest. 1978; 61:72-78. [PubMed: 618914]

[38]. Harvey SJ, Jarad G, Cunningham J, Rops AL, van der Vlag J, Berden JH, Moeller MJ, Holzman LB, Burgess RW, Miner JH. Disruption of glomerular basement membrane charge through podocyte-specific mutation of agrin does not alter glomerular permselectivity. Am. J. Pathol. 2007; 171:139-152. [PubMed: 17591961]

[39]. Goldberg S, Harvey SJ, Cunningham J, Tryggvason K, Miner JH. Glomerular filtration is normal in the absence of both agrin and perlecan-heparan sulfate from the glomerular basement membrane. Nephrol. Dial. Transplant. 2009; 24:2044-2051. [PubMed: 19144998]

[40]. van den Hoven MJ, Wijnhoven TJ, Li JP, Zcharia E, Dijkman HB, Wismans RG, Rops AL, Lensen JF, van den Heuvel LP, van Kuppevelt TH, Vlodavsky I, Berden JH, van der Vlag J. Reduction of anionic sites in the glomerular basement membrane by heparanase does not lead to proteinuria. Kidney Int. 2008; 73:278-287. [PubMed: 18046314]

[41]. Axelsson J, Sverrisson K, Rippe A, Fissell W, Rippe B. Reduced diffusion of charge modified, conformationally intact anionic Ficoll relative to neutral Ficoll across the rat glomerular filtration barrier in vivo. Am. J. Physiol. Renal Physiol. 2011; 301:F708-F712. [PubMed: 21775478]

[42]. Haraldsson B, Nystrom J, Deen WM. Properties of the glomerular barrier and mechanisms of proteinuria. Physiol. Rev. 2008; 88:451-487. [PubMed: 18391170]

[43]. Hausmann R, Kuppe C, Egger H, Schweda F, Knecht V, Elger M, Menzel S, Somers D, Braun G, Fuss A, Uhlig S, Kriz W, Tanner G, Floege J, Moeller MJ. Electrical forces determine glomerular permeability. Journal of the American Society of Nephrology: JASN. 2010; 21:20532058. [PubMed: 20947631] 


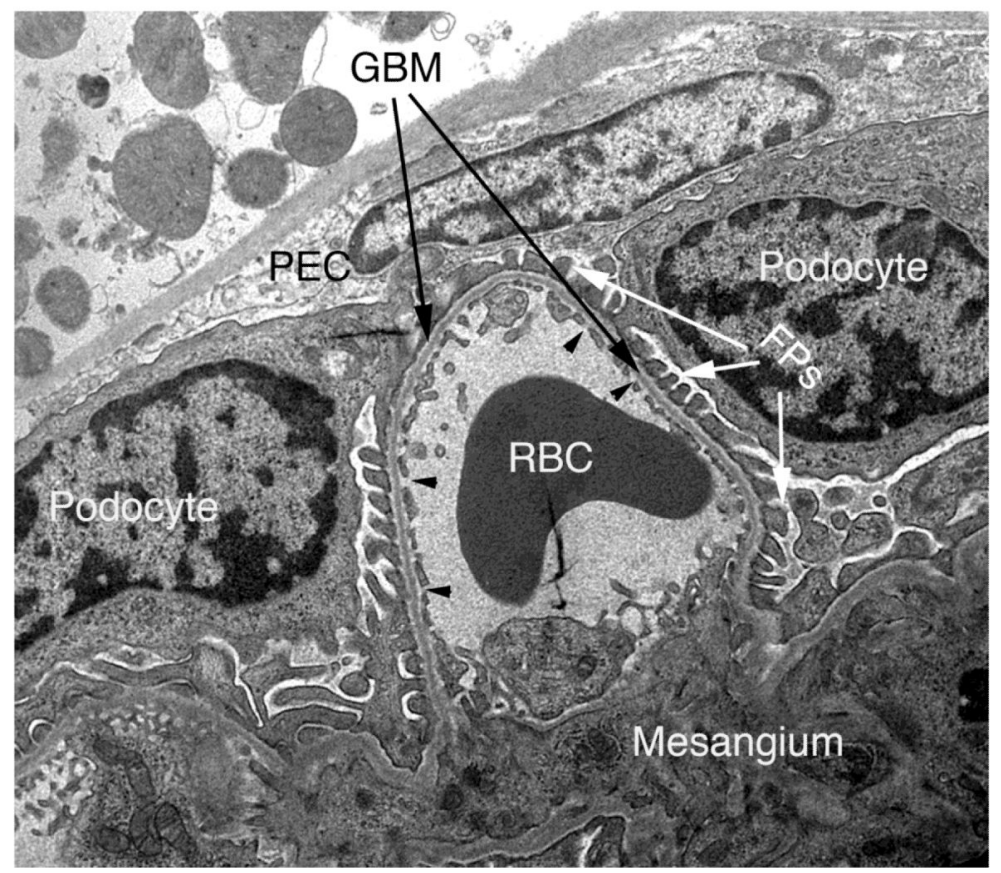

Figure 1.

Ultrastructure of a typical glomerular capillary loop. A red blood cell (RBC) is present in the capillary lumen, which is lined by an endothelial cell with fenestrations (black arrowheads). The glomerular basement membrane (GBM) is a ribbon-like extracellular matrix that lies between the endothelium and the podocyte foot processes (FPs). The mesangium contains mesangial cells and their associated matrix. A parietal epithelial cell (PEC) is visible lining Bowman's capsule. 


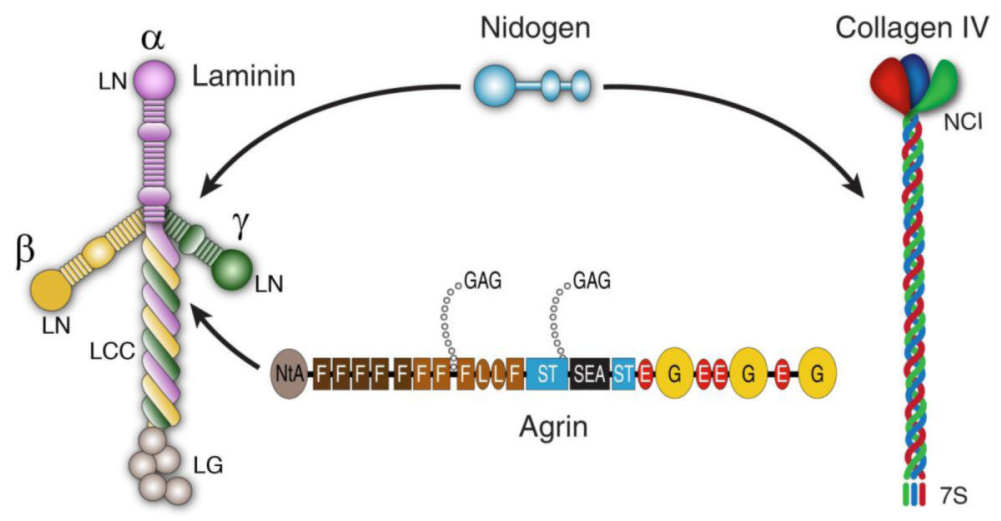

Figure 2.

The major components of basement membranes: laminin, type IV collagen, nidogen, and heparan sulfate proteoglycan (agrin is shown due to its prevalence in the GBM, though perlecan is more widely found in basement membranes). Collagen IV is a triple helical protein with $\mathrm{C}$-terminal noncollagenous domains (NC1) and N-terminal 7S domains; these are important in network formation. Laminin $\alpha, \beta$, and $\gamma$ chains assemble with each other via the laminin coiled-coil (LCC) domain. Laminin N-terminal (LN) domains are involved in polymerization of trimers, which initiates basement membrane formation. The C-terminal laminin globular (LG) domain contains binding sites for cell surface receptors. Agrin, a modular protein containing glycosaminoglycan (GAG) side chains, binds to the laminin long arm via the $\gamma 1$ chain, whereas nidogen binds to the short arm of laminin $\gamma 1$ as well as to collagen IV. 


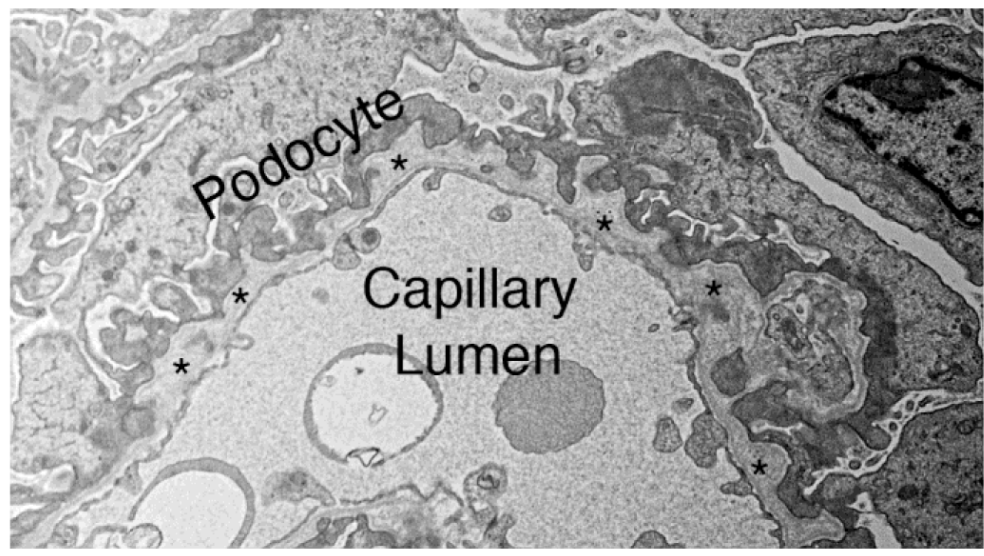

Figure 3.

GBM lesions in a mouse model of Alport syndrome (hereditary nephritis). The mouse is homozygous for a null mutation in $\mathrm{Col} 4 \mathrm{a} 3$ and therefore lacks the collagen a $3 \mathrm{a} 4 \mathrm{a} 5$ (IV) network. Note the outpocketings of the GBM (asterisks) that project toward the podocyte, which has lost much of the normal foot process architecture. 

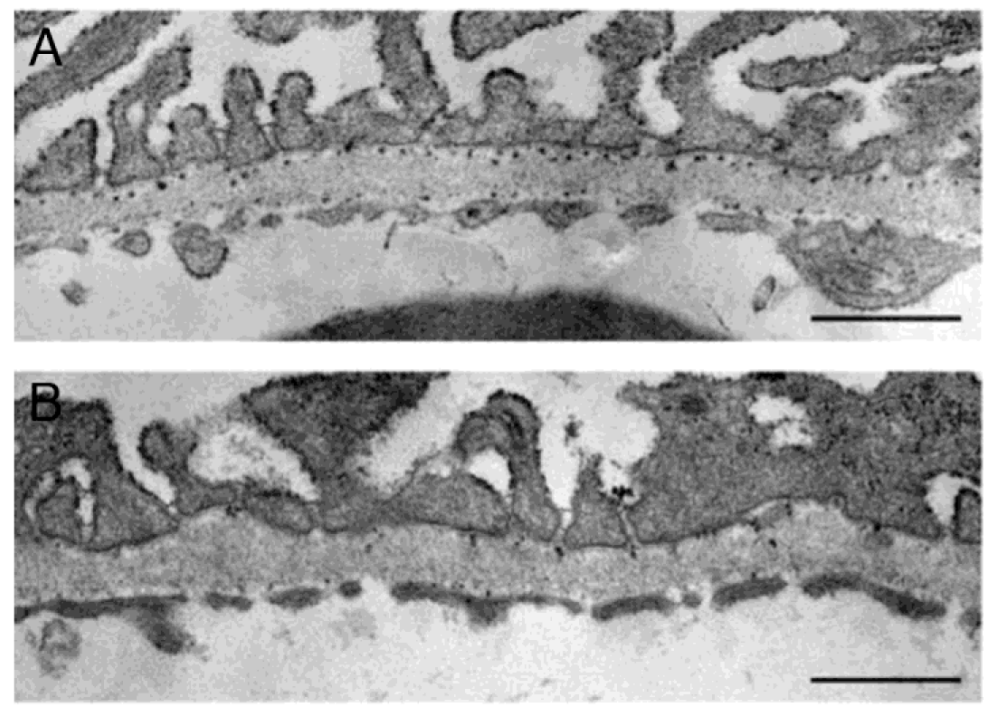

Figure 4.

Detection of a GBM charge defect in a podocyte-specific agrin mutant mouse using the cationic probe polyethyleneimine to detect anionic sites. In the control, discrete subepithelial anionic sites are revealed (A), but these are significantly reduced in the mutant (B). Despite this reduction in anionic charge, mutants displayed no detectable filtration barrier defects. 